

\section{The IMAGES Project (www.images-1.over-blog.org) and the IMAGES Project 2011 Publication IMAGES - Films as Spaces of Cultural Encounter}

The project IMAGES (www.images-1.over-blog.org) has been planned and scheduled as a series of conferences, publications, exhibitions and online photo contests for the years 2011-2014. It has been initiated by the research focus Cultures in Contact, which is part of the humanities research platform CEnT (Cultural Encounters and Transfers) based at Leopold-Franzens-University in Innsbruck/ Austria. The senior project partner is Kadir Has University in Istanbul/ Turkey. The idea for the project has been developed by Assoc. Prof. (Privatdozent) Dr. Veronika Bernard (University of Innsbruck) and Assoc. Prof. Dr. Serhan Oksay (Kadir Has University).

IMAGES is an interdisciplinary project, and it strongly relies on the cooperation with international academic and non-academic partners.

IMAGES deals with the discourse of cultural encounters within the context of social co-existence. The project defines "discourse of cultural encounters" as the discourse within the context of cultural encounters and as the discourse on cultural encounters. Within this scope, the project deals with both verbal and non-verbal communication and focuses on the topical fields of cultural encounter, poverty, and migration.

IMAGES adapts a cultural studies definition of the term "culture". Cultural studies, basically, define culture by the concept of the group, seeing culture as the sum of all the features and ways of behaviour people show and adapt deliberately in order to become distinct from others and to form their specific identities.

IMAGES further embraces perspectives on cultural phenomena taken by communication studies. The project starts from the idea that the images you form (of you and of others) essentially shape relations and communication between both individuals and communities, and at the same time are their results. Contemporary communication studies introduce images (as the images an individual holds of his or her own self, and the images others form of you) to a communicative system formed of values, evaluation and selective perception. No matter which our values are, as a whole they build that very system by which we evaluate and judge the ways others act, look and speak in order to find out whether they fit in with our values. In case they do, there is the realistic chance of a positive and fruitful communicational process; in case they do not, communication will go wrong and end soon - in a comparatively unspectacular way by cutting communicational ties or in a rather dramatic way by leading into conflict.

Intercultural communication studies analyse these mechanisms with individuals from different cultures. From an intercultural perspective (intercultural) communication means that you open your own culture to ideas rooting in the other's culture by dropping own cultural ideas and including ideas rooting in the communication partner's culture. This is possible only, however, if cultures have a minimum number of ideas in common. Intercultural communication aims at increasing the number of ideas cultures have in common; increasing their number makes the difference between successful and not successful (intercultural) communication. In case there are no ideas in common, intercultural communication will be impossible and the cultures involved will not be able to reach a better mutual understanding.

Considering the communicative mechanism of selective perception, IMAGES understands cultural encounters and the possible ways they take as circular patterns, and it sees itself as part of these circular patterns: the academic discourse on cultural encounters, poverty and migration, which will be dealt with in the conference and publication series, will be contrasted to the results originating from the online photo contests and being 
presented to the public in the exhibition series, which document the non-verbal everyday-life discourse. In this way IMAGES adds to the critical discussion on the definitions of cultural encounters.

The IMAGES project publication series opens with the CINEJ 2011 special issue IMAGES - Films as Spaces of Cultural Encounter, which is available as an online and as a printed edition. The volume includes papers proposed for the IMAGES project conference IMAGES - Films as Spaces of Cultural Encounter (Istanbul, Kadir Has University, 1-4 June 2011). The conference was designed as a public 4-days international and interdisciplinary English language conference, co-organized by the University of Innsbruck based research platform CEnT - Cultural Encounters and Transfer and Kadir Has University (Istanbul) in cooperation with CINEJ, the international refereed online cinema journal published by the University of Pittsburgh (http://cinej.pitt.edu). It intended to bring together senior scholars with $\mathrm{PhD}$ students, and postdoctoral academics, without following the classical keynote speaker pattern but rather inviting all speakers to present their research findings in 30 minute paper presentations (including 10 minutes for discussion) in plenary sessions. The conference concept also reserved room for presentations of creative works focussing on the conference topic.

Having applied the IMAGES project context on the conference topic, the CINEJ 2011 special issue IMAGES - Films as Spaces of Cultural Encounter includes articles analysing films as spaces of cultural encounters from a cultural studies perspective in general, as well as from inter-cultural, multi-cultural, transcultural, semiotic, communication centred, historical, political, and all related perspectives.

Innsbruck and Istanbul Veronika Bernard and Serhan Oksay (IMAGES project directors) 